\title{
A NECESSIDADE DE REAFIRMAÇÃO DO DIREITO DO TRABALHO COM BASE NA DOUTRINA MARXISTA
}

Diego Budel. ${ }^{1}$

\section{RESUMO}

Trata-se de Revisão bibliográfica interdisciplinar voltada para o Direito Do Trabalho e suas matérias propedêuticas como a sociologia do trabalho, economia do trabalho e economia política relativamente ao trabalho mediante lições de Karl Marx e de consagrados interpretes de seus textos. Aborda-se o trabalho e as características da exploração do trabalho humano pós-revolução industrial com enfoque na importância do salário e no conflito de interesses do capital no embate com o trabalho ressaltando a importância de reafirmar constantemente o Direito do Trabalho e de interpretar corretamente influxos do capital como a Reforma Trabalhista de 2017.

Palavras-Chave: Direito do Trabalho. Preço do Trabalho. Questão Social. Reforma Trabalhista de 2017. Doutrina Marxista.

\section{THE NEED TO REAFFIRM LABOR LAW BASED ON MARXIST DOCTRINE}

\begin{abstract}
This is an interdisciplinary bibliographical review focused on labor law and its propaedeutic subjects such as the sociology of labor, labor economics and political economy in relation to work through the lessons of Karl Marx and consecrated interpreters of his texts. we study the work and characteristics of the exploitation of post-industrial human labor with a focus on the importance of salary and the conflict of interests of capital in the struggle with the work emphasizing the importance of constantly reaffirming Labor Law and correctly interpreting inflows of capital as the Labor Reform of 2017.
\end{abstract}

Keywords: Labor Law. Labor Price. Social issues. Labor Reform 2017. Marxist Doctrine.

\section{INTRODUÇÃO}

Essa pesquisa tem como objeto a necessidade de reafirmação constante do Direito do Trabalho partindo de uma análise propedêutica pautada em autores de sociologia do trabalho, história do trabalho, economia do trabalho e economia política de base Marxista. Diante de retrocessos nos direitos dos trabalhadores surge o problema que norteou essa revisão bibliográfica, qual seja: É necessário reafirmar constantemente a importância do Direito do Trabalho mesmo ele sendo um ramo autônomo e consagrado do Direito?

\footnotetext{
${ }^{1}$ Advogado Especialista em Direito e Processo do Trabalho, Ex-Juiz-Leigo do TJ/BA, Bolsista da Fapesb no curso de Mestrado em Políticas Sociais e Cidadania, Aluno Especial no Mestrado em Direito da UFBA. Endereço Postal: Rua Adelina de Sá, no 10 - Centro - Camaçari/Bahia, CEP 42.800-060. E-mail: Diegobudel.adv@gmail.com.br.
} 
A aferição do contexto em que se insere o trabalho no sistema capitalista e as consequências disso serão elucidadas mediante conceitos presentes no escólio de Marx em suas obras e em interpretes das obras de Marx. Sendo que esse caminho deixará clara a evolução histórica e a finalidade do Direito do Trabalho, que devem ser parâmetro para a interpretação e compreensão da Reforma Trabalhista de 2017 inclusive no plano jurídico, sem olvidar a concepção e filtragem da aludida reforma com base nos direitos e valores fundamentais consagrados na Constituição, especialmente os de índole trabalhista.

Em tempos de retrocesso nos direitos fundamentais em vários países do mundo, especialmente no que tange aos direitos fundamentais sociais e trabalhistas, que têm sido objeto das chamadas reformas trabalhistas e previdenciárias, como as que estão em curso atualmente no Brasil e que já foram implementadas nos últimos anos ao redor do mundo, como por exemplo no México e na Espanha ressurge a necessidade de afirmação do Direito do Trabalho de modo a ressaltar sua importância para a sociedade e para um desenvolvimento social e econômico adequado.

A doutrina vem ressaltando a necessidade de atualmente tornar efetivos os direitos que já estão positivados no sistema jurídico, considerando ultrapassada a necessidade de afirmá-los (Bobbio), entretanto, diante do retrocesso social que tem ocorrido em vários países motivados por uma onda neoliberal lastreada na crise econômica ressurge com mais força que nunca a necessidade de reafirmar tais direitos.

Sabendo que nos momentos de crise econômica, sói ocorrer a atribuição da culpa das crises ao custo dos Direitos trabalhistas e sociais, é possível dizer que reafimar a importância do Direito do Trabalho é uma necessidade constante diante da propensão do capitalismo a produzir crises (Harvey). Harvey deixa claro que o capitalismo está propenso a crises, e que elas ocorrem de tempos em tempos, tendo como alvo mais comum para sua suposta solução o disciplinamento da força de trabalho.

Ele aponta como paliativo para lidar com as crises o deslocamento geográfico da demanda por trabalho, atualmente, entretanto, cresce fortemente juntamente com a ideologia neoliberal uma tendência de tentativa de desregulamentação da relação de trabalho ou de mudança da racionalidade ínsita ao Direito do Trabalho. Diante desse panorama, premente é a necessidade de afirmar sua necessidade e importância.

O caminho mais adequado para a demonstração da relevância impar do ramo laboral do Direito é a abordagem sociológica que trata da questão social e da evolução da exploração do trabalho humano ou da relação capital x trabalho no contexto histórico 
iniciado com a revolução industrial. Desse modo, é com uma análise histórica e com uma perspectiva sociológica que se percebe mais facilmente o papel exercido pelo Direito do Trabalho na atualidade.

\section{O TRABALHO HUMANO}

Para ficar mais claro o tema proposto e o caminho a ser percorrido, convém conceituar alguns termos que serão centrais no desenrolar da presente pesquisa. Inicialmente a concepção de trabalho (lato sensu) é o parâmetro inicial para o desenrolar dos sucessivos aspectos a serem abordados. Importante distinção e conceituação é feita por Braverman ao ressaltar que "O trabalho humano é consciente e proposital, ao passo que o trabalho dos outros animais é instintivo." (1987, p. 50). Assim o autor diferencia o trabalho humano daquela atividade desempenhada por outros animais, como por exemplo uma aranha ao tecer sua teia. Isso é motivado pela própria constituição diferenciada do ser humano, pois continua Braverman contrastando que "no trabalho humano o mecanismo regulador é o poder do pensamento conceptal, que tem origem em todo um excepcional sistema nervoso central. (1987, p. 51).

Embora possa parecer uma diferença um tanto elementar esta aqui enfatizada entre o labor humano e as atividades dos animais, ela é crucial para que possamos entender a relevância do trabalho humano e como ele foi modificado pelo modo capitalista de produção. Braverman se vale das lições de Marx para aprofundar tratar da relevância do trabalho enquanto tal.

O trabalho como atividade proposital, orientado pela inteligência, é produto especial da espécie humana. Mas esta, por sua vez, é produto especial desta forma de trabalho. "Ao agir assim sobre o mundo externo e transformá-lo, ele ao mesmo tempo modifica sua própria natureza. (MARX Apud BRAVERMAN, 1987 p. 52)

Nessa toada, destaca-se que enquanto os animais continuam exercendo suas funções inatas e instintivas, os traços instintivos do trabalho humano a muito foram atrofiados pelas formas sociais de produção (BRAVERMAN, 1987, p. 53). Para arrematar a diferenciação, o mesmo autor destaca que a concepção pelo homem de um trabalho pode ser continuada por outro, bem como "a ideia concebida por uma pessoa pode ser executada por outra pessoa." (BRAVERMAN, 1987, p. 53).

Outra diferença decisiva do ponto de vista da espécie humana, considerando o proprietário de força de trabalho genericamente concebida é que do ponto de vista da espécie Rev. do Dir. do Trabalho e Meio Ambiente do Trabalho | e-ISSN: 2525-9857 | Salvador | v. 4 | n. 1 | p. 40 - 58 | Jan/Jun. 2018 
humana todo indivíduo é proprietário de uma porção da força de trabalho total da comunidade, da sociedade e da espécie. (BRAVERMAN, 1987, p. 54)

A partir do momento em que o trabalho é dominado e modelado pelo capital, apesar de sua característica de fazer parte do próprio corpo do trabalhador, exigindo sua dedicação física, com implicações na existência em si do homem, por não poder ser separado de seu corpo e sua vida, o trabalho em favor de outrem implica a abstenção de atividades em prol de si mesmo. Apesar disso, é no trabalho humano que o capitalista acha nele, em razão inclusive de seu caráter plástico, o recurso essencial para a expansão do seu capital. (BRAVERMAN, 1987, p. 57).

Em razão de tal plasticidade o trabalho humano é "infinito em potencial mas limitado em sua concretização", sendo fundamental para o capitalista o controle sobre o processo de trabalho, o que culmina na questão da gerência. (BRAVERMAN, 1987, p. 58-59). E é em razão necessidade do capital de se apropriar do processo de trabalho que as relações de trabalho se multiplicam após a revolução industrial, e que essa relação jurídica entre o capitalista e o proletário se torna uma das mais, ou mesmo a mais, frequente relação jurídica de nossa sociedade.

O sistema capitalista se torna então dependente dessas relações e da disponibilidade de trabalhadores que darão seus préstimos na produção dos bens e serviços gerando ganho patrimonial para outrem. Por isso a necessidade de que essa força de trabalho se reproduza, ou seja, é preciso que mais e mais pessoas desejem ofertar sua força de trabalho e que isso também ocorra com relação as futuras gerações. Está em questão a reprodução da força de trabalho.

Segundo Paul Singer, a reprodução da força de trabalho abrange tanto sua manutenção, ou seja, a sobrevivência do trabalhador mediante a possibilidade de suprir suas necessidades básicas, quanto a reposição, ou seja, a substituição dos inválidos e aposentados. O primeiro fundamento da reposição é a existência de um salário que permita essa reprodução, mas não se resume a isso, pois há influência do modo de vida e das relações sociais de um determinado momento histórico nessa reprodução. Sendo que ele destaca ainda a necessidade de fornecimento de alguns bens de uso por parte do Estado, como educação para o trabalho e saúde. (1977, p. 118-119).

Ao proceder uma digressão histórica Singer demonstra como a apropriação do trabalho feminino (e do trabalho da criança, ambos comumente chamados de meias-forças) 
colaborou para a diminuição dos salários em geral e a submissão de toda a família ao domínio do capital.

\section{OS REFLEXOS DO CAPITALISMO NO MUNDO DO TRABALHO}

No entanto, enquanto prevalecia essa situação de aumento da utilização do trabalho feminino, constatou-se o aumento da mortalidade infantil e da desnutrição, maus tratos com os filhos e envenenamento de crianças. (SINGER, 1977, p. 122-123) Sendo que quando houve um crescimento continuo dos salários reais os índices de mortalidade infantil diminuíram (p. 125). "Marx mostra, desta maneira, que o capital, tendo plena e ilimitada liberdade de explorar a força de trabalho que lhe está submetida, tende a destruí-la." (SINGER, 1977, p.124).

De outra banda o aumento crescente dos salários reais melhorou a qualidade de vida e de consumo da classe operária, que pôde manter a mãe de família em casa e melhorar o padrão de consumo, que envolve desde carnes e frutas que melhoraram a nutrição das crianças, até bens duráveis como roupas e sapatos. (SINGER, 1977, p.125-126).

Esse movimento de crescimento ou diminuição do poder de compra dos salários influencia na reposição da força de trabalho de maneira diferida como de maneira imediata, pois o aumento salarial permite às mulheres dos operários que elas se dediquem às atividades domésticas ao invés do trabalho fabril para complementar a renda familiar.

Nota-se então, um ciclo vicioso na diminuição dos salários, pois o seu rebaixamento cria a necessidade de que mais membros das famílias busquem e se submetam ao trabalho assalariado, aumentando a oferta de mão de obra e desvalorizando cada vez mais o trabalho humano em razão da sua disponibilidade cada vez mais abundante. "As mulheres de proletariado só permanecem no mercado de trabalho enquanto a insuficiência dos ganhos dos seus homens as coage a tanto, preferindo ficar em casa e cuidar de sua família quando isso se torna viável." (SINGER, 1977, p. 130).

Diante desse cenário, resta claro que a classe trabalhadora se adapta aos movimentos ditados pelo capital, entretanto, o próprio capital, com tais movimentos de aumento ou diminuição da austeridade relativamente ao tratamento dado à força de trabalho, ele influencia e por vezes controla, ao menos indiretamente, a própria reprodução da força de trabalho.

Rev. do Dir. do Trabalho e Meio Ambiente do Trabalho | e-ISSN: 2525-9857 | Salvador | v. 4 | n. 1 | p. 40 
Esse controle exercido pelo capital é elemento essencial para o processo produtivo capitalista e consequentemente para a variação do nível dos salários, pois "Marx atribui as alterações do nível de salários essencialmente a mudanças no exército industrial de reserva" (SINGER, 1977, p. 139). Daí a importância do Direito do Trabalho para, impondo limites civilizatórios à exploração do trabalho pelo capital, regular a relação capital trabalho de maneira saudável, de modo a garantir cada vez mais o acesso dessa parcela da espécie responsável pelo trabalho utilizado na produção aos seus resultados.

O aumento dos salários reais não só assegurou a efetiva reprodução da força de trabalho, permitindo tanto a manutenção do trabalho adulto quanto sua reprodução no fim de sua vida produtiva, mas ocasionou uma ampliação da demanda interna de consumo que tornou possível o lançamento de uma nova série de "novos produtos", que viriam caracteriza a segunda fase da Revolução Industrial ou o que é considerado por vários autores como a 2a Revolução Industrial. (SINGER, 1977, p. 133)

Porém, dentre outros elementos que influenciam a manutenção e a reprodução da força de trabalho, se encontra a diminuição dos postos de trabalho em decorrência do avanço tecnológico eliminador de postos de emprego. Singer ao tratar das inovações tecnológicas destaca que existem inovações que se constituem novos produtos (v.g. a máquina de costura). Nesse caso específico a colocação do produto no mercado pode gerar mais empregos do que os eliminados pela nova tecnologia em si.

O fato de a máquina de costura ter-se tornado um bem de consumo - portanto um "novo produto" - fez com que o emprego gerado em sua produção certamente superasse, de muito o emprego que sua utilização industrial eliminou. (SINGER, 1977, p. 133)

Essas inovações tecnológicas que se constituem produtos, ao mesmo tempo que geram novos empregos e comodidades (e que igualmente suprimem outros postos de emprego) - quando máquinas de uso doméstico permitem que a mãe de família possa oferecer novamente sua força de trabalho no mercado de trabalho pela criação de tempo livre - porém as inovações tecnológicas que constituem produtos influenciam nas condições político-econômicas que despertam novas necessidades e novas demandas geradoras de pressão social por melhores condições de trabalho. (SINGER, 1977, p. 136-138)

As condições econômicas e políticas que determinam o nível de reprodução da força de trabalho no capitalismo sofreram uma mutação a partir da segunda metade do século passado [...].

A partir da mutação, o elemento social na determinação do valor da capacidade de trabalho passou a adquirir valores positivos e crescentes. As situações das duas partes na luta de classes de certa maneira se inverteram: os trabalhadores passaram a pressionar no sentido de incorporar ao seu "padrão tradicional de vida" os "novos produtos", que o avanço tecnológico ia proporcionando, ao passo que os capitalistas se limitavam a contrapressionar no sentido de retardar e limitar a expansão desse círculo de necessidades, que o salário monetário tinha que permitir ao trabalhador satisfazer. (SINGER, 1977, p. 137-138) 
Embora essas pressões possam ser comumente vistas de modo negativo pelo capital, o que se quer enfatizar aqui é que até certo limite, do mesmo modo que a diminuição continuada do nível salarial provoca um ciclo vicioso, em contrapartida, o aumento generalizado desse nível acarreta um ciclo virtuoso decorrente da criação de mercado e do aumento do consumo, que são ingredientes essenciais para o desenvolvimento e o lucro no modelo econômico capitalista. Vejamos:

$\mathrm{O}$ efeito deste aumento foi reforçar o movimento inicial: salários reais maiores expandiram o mercado interno, o que estimulou a acumulação nas próprias metrópoles, acarretando um aumento maior da demanda por força de trabalho. Os trabalhadores alcançavam salários mais altos e os capitalistas respondiam a estes salários maiores não com uma racionalização, não com o aumento da composição orgânica em tal medida que reforçasse de novo o exército industrial de reserva; não o faziam porque, apesar dos salários mais altos, eles obtinham lucros mais altos ainda. (SINGER, 1977, p. 140)

Tendo em vista os efeitos benéficos do aumento generalizado dos níveis salariais vale ressaltar que Singer faz a observação quanto à centralidade da influência exercida nesse nível pelo crescimento ou diminuição do exército industrial de reserva, pois o poderio político-social do movimento operário, suas aspirações, o surgimento de novos produtos, novas tecnologias e suas características intrínsecas também exercem influência substancial nesse fenômeno. (SINGER, 1977, p. 145).

Ao tratar do exército industrial de reserva, se faz pertinente uma digressão pontual para abordar o conceito de superpopulação relativa, que é abordada por David Harvey com base no escólio de Marx mediante sua divisão em três extratos, os das superpopulações flutuante, latente e estagnada e enfatiza a influência substancial dos avanços tecnológicos no estrato flutuante e suas consequências negativas para as reivindicações da classe trabalhadora.

Por superpopulação "flutuante" ele entende as pessoas que já estão proletarizadas, que já são trabalhadoras assalariadas de tempo integral ou que, são temporariamente dispensadas do trabalho por alguma razão, sobrevivem de algum modo durante o período de desemprego, antes de serem reabsorvidas no emprego quando as condições para a acumulação melhoram. [...]

A superpopulação latente são pessoas que ainda não foram proletarizadas. $\mathrm{Na}$ época de Marx, o termo referia-se particularmente às populações camponesas ainda não absorvidas pelo sistema de trabalho assalariado. [...] também pode incluir produtores pequeno-burgueses independentes e artesãos que foram deslocados pelo grande capital e forçados a ingressar no mercado de trabalho.

$[\ldots]$

$\mathrm{O}$ terceiro extrato é a superpopulação estagnada. Refere-se àquela parte da população empregada de maneira muito irregular e particularmente difícil de mobilizar. A camada mais baixa da superpopulação estagnante é situada por Marx "na esfera do pauperismo" e inclui "vagabundos, delinquentes e prostitutas"[...]. $[\ldots]$

Rev. do Dir. do Trabalho e Meio Ambiente do Trabalho | e-ISSN: 2525-9857 | Salvador | v. 4 | n. 1 | p. 40 -58 | Jan/Jun. 2018 
O segundo modelo de acumulação de Marx depende fundamentalmente das reservas criadas pelo desemprego induzido pelo avanço tecnológico. (HARVEY, 2013, p. 267-268)

Esses conceitos demonstram como Marx classifica as parcelas que compõem a classe trabalhadora e esclarece como as influências do capital no mundo do trabalho são diferentes a depender da parcela da classe trabalhadora analisada. Desse modo, é elucidativo utilizar a classificação para fins de análise e compreensão dos efeitos oriundos dessa relação secular.

\section{A QUESTÃO SOCIAL}

Convém destacar que embora as pressões sociais da classe trabalhadora tenham sido consideradas como fonte de mudanças nos padrões de nível salarial de determinadas épocas, em diversos momentos e lugares as reivindicações que envolvem a questão social foram criminalizadas e tratadas como questão de polícia.

Não é episódica, ao contrário, é permanente, a convicção de setores dominantes e governantes, civis e militares, de que as manifestações operárias e camponesas ameaçam a ordem pública, a paz social, a segurança, a ordem estabelecida, ou "a lei e a ordem". Qualificam essas manifestações como problemas de polícia ou também militar. (RAMOS Apud IANI, 1991, p. 4)

No entanto tal criminalização tem o efeito de escamotear a produção da pobreza como consequência natural do modo de produção capitalista, o que na linha do que se está a defender no presente trabalho reitera o papel de extrema relevância do Direito do Trabalho no controle dessas mazelas que são congênitas ao modelo econômico vigente e não podem ser desprezadas, nem mesmo diante do discurso vazio e infundado de imprestabilidade desse insigne ramo do Direito.

É enganoso sugerir que os dois brasis pouco ou nada têm a ver um com o outro. A análise atenta das relações, processos e estruturas de dominação política e apropriação econômica permite demonstrar que os processos da economia têm raízes na pauperização relativa - e as vezes absoluta - de trabalhadores da cidade e do campo. Isto é, os "participantes" e os "excluídos" estão atados por relações, processos e estruturas que reiteram continuamente, em distintas formas, diferentes regiões; em geral por intermédio de instrumentos e técnicas controlados pelos que mandam, ou seja, uma parcela dos "participantes". (IANI, 1991, p. 5)

A criminalização se mostra um dos instrumentos, mas como se percebe pelo caminho percorrido na presente pesquisa, para o controle do exército industrial de reserva, que ocupa posição estratégica no embate capital-trabalho e exerce sua influência de modo mais sofisticado e oculto.

O interesse da classe capitalista é administrar a oferta de trabalho para criar e perpetuar um exército de reserva (numa combinação de flutuante e latente) e assim manter salários baixos, ameaçar os empregados com demissões iminentes, 
dispersar a organização de trabalho e aumentar a intensidade de trabalho dos que continuam empregados. (HARVEY, 2013, p. 270)

O Direito do Trabalho, certa torna as relações de emprego mais duradouras mediante garantias de emprego que desmotivam a extinção desses vínculos ou mesmo impedem juridicamente a dissolução do vínculo empregatício. Além disso, fixa limites de jornada e protege os representantes da classe trabalhadora no exercício da representação, minimizando as possibilidades e efeitos dos métodos de pressão tradicionalmente utilizados pelos titulares dos meios de produção.

Além disso, por sua gênese, o Direito do Trabalho acarreta como efeito prático a característica social de obstar a expropriação imoral da força de trabalho pelo capital e tratar gradativamente dos efeitos nocivos da produção de desigualdade pelo nivelamento da exploração da força de trabalho dentro de certos limites, ensejando um progresso constante no seio da sociedade.

O Direito do trabalho atua na moralização da relação capital-trabalho produz o efeito clássico de padronização pela formalização das relações empregatícias necessárias para dar dinamicidade às relações entre os indivíduos. O que é feito numa atuação governamental de padronização que visa a assegurar condições de trabalho que observem a dignidade humana do trabalhador. Sem as limitações impostas pelo direito do trabalho, Marx destaca:

Portanto, para Marx, "diante desse tipo de racionalidade do sistema capitalista, os
salários tenderiam a ser, cada vez mais, salários de sobrevivência, isto é, salários
que o capitalista paga apenas como forma de garantir que a força de trabalho de
que necessita se manterá viva e poderá se reproduzir, tornando-se equivalente a
apenas uma parte do valor que produz, enquanto o restante (mais-valia) entrará na
composição do lucro capitalista - garantindo, assim, o funcionamento e a
reprodução do próprio sistema. (MARX Apud GUIMARÃES, 2013, p. 423)

Tal padronização tem diversas características antagônicas, pois se de um lado garante direitos, de outro, por limitações fáticas inerentes à própria atividade legislativa e à infinidade de fatos sociais passíveis de regulação pelo Direito, a lei não observa expressamente as necessidades específicas de cada categoria profissional, não obstante a possibilidade de pactuação no plano individual e no plano coletivo trabalhista.

Se de um lado o Direito do Trabalho assegura o mínimo de direitos necessário para assegurar a dignidade do trabalhador para um determinado contexto histórico, de outro torna a pactuação e ruptura da relação mais dinâmica, mediante a utilização de mecanismo jurídico similar ao contrato de adesão, que facilita a contratação e também a rotatividade (que gera instabilidade no posto de emprego) da utilização da mão de obra. 
Essa política é apontada por Sombra como "Dirigismo Contratual" (SOMBRA, 2011), porém, vale ressaltar que o dirigismo contratual não é a finalidade do direito do trabalho, pois a implementação de políticas econômicas pelo Estado possui outros meios mais adequados.

Aos poucos, começa-se a equacionar a questão. As exigências da economia, os desenvolvimentos das forças produtivas e as possibilidades da industrialização exigem que as relações de produção sejam formalizadas, institucionalizadas. Desse modo, o trabalho pode atender melhor às exigências do desenvolvimento e diversificação do sistema econômico. "Modernizar" as relações trabalhistas, as condições de oferta e de demanda de força de trabalho, pode ser uma exigência do mercado, da grande empresa, da industrialização, do comércio exterior e até mesmo do capital estrangeiro.

Esse é o contexto em que intelectuais, políticos, membros de governo e empresários começam a reconhecer a conveniência de equacionar a questão social. Para Sampaio Doria, o trabalho está no centro da questão social. (IANI, 1991, p. 6)

O que tange ao conceito de questão social, embora haja divergência a depender do autor que se adote, podemos afirmar que ela gira em torno das questões da pobreza, das más condições de trabalho, da desigualdade e da prevenção dos riscos sociais (como doença e invalidez).

Mas merece destaque maior o fato de que independente da utilização de um modelo teórico mais ou menos adequado, é a intenção dos governantes, dos participantes e dos "que mandam" que possui maior impacto em sua solução, pois: "Não há questão social habitação, alimentação, educação, saúde e outras - cuja solução exija mais do que apenas a boa vontade e diligência por parte dos que respondem pela preservação do nosso patrimônio social e histórico" (SIMONSEN Apud IANI, 1991, p. 7).

Embora a questão social seja uma constante na sociedade submetida ao modo de produção capitalista percebe-se ondas de avanços nos direitos sociais e momentos de retração ao longo de décadas. Os avanços dos direitos da classe trabalhadora, embora fosse desejável que ocorressem de modo contínuo, na prática ocorrem e movimentos pendulares. O que novamente ressalta a necessidade de afirmação dos direitos trabalhistas e de sua relevância para um desenvolvimento salutar da sociedade no passar das décadas diante dos efeitos perversos do capitalismo.

Acompanhando as mudanças, o período de garantia da reprodução pelo trabalho, como direito conquistado pelos movimentos de trabalhadores, é seguido por um período de perdas ou rupturas do bem-estar, mesmo entre os trabalhadores estáveis inseridos nos setores produtivos. (GUIMARÃES, 2013, p. 426)

Mesmo se considerando a recuperação do mercado de trabalho indicada pelo aumento de trabalhadores com carteira assinada a partir de 2006, não se elimina a precarização[...]. (GUIMARÃES, 2013, p. 427) 
Destacada a relevância do trabalho e do Direito do Trabalho para o tratamento da questão social, vale aprofundar a abordagem analítica dos efeitos e consequências oriundos da relação capital-trabalho, elucidando conceitos de valor e preço do trabalho e das mercadorias, a partir de então, mediante a utilização da perspectiva de Marx em suas lições de maneira direta, dispensando por hora os eminentes interpretes que já foram abordados, sem olvidar sua especial relevância, dadas as contribuições pertinentes para a elucidação do objeto da pesquisa.

\section{VALOR E PREÇO DO TRABALHO SEGUNDO KARL MARX}

Não obstante possamos perceber esse avanço em termos absolutos na quantidade de mão de obra demandada pelos meios de produção, em termos relativos há uma diminuição da demanda de mão de obra e consequentemente do emprego de força de trabalho (que Marx chama de capital variável). Em "O Capital” Marx aponta como principal causa desse fenômeno o fato de uma parte cada vez maior do lucro ser investida em aquisição de maquinário, gestão, infraestrutura e outras espécies de capital constante, gerando um emprego cada vez menor de força de trabalho vivo para um volume cada vez maior de produção.

\footnotetext{
Seu valor aumenta, portanto, de modo absoluto, mas não proporcionalmente a seu volume. $\mathrm{O}$ aumento da diferença entre capital constante e capital variável é, por conseguinte, muito menor do que o da diferença entre a massa dos meios de produção e a massa da força de trabalho em que são convertidos, respectivamente, o capital constante e o variável. A primeira diferença aumenta com a última, mas em grau menor. (MARX, 2013, p. 847)
}

Essa sistemática tem duas consequências, que percebemos de plano com base nas lições de Marx, uma já nos referimos anteriormente, que é a tecnologia eliminadora de postos de emprego (uma tendência inexorável no modo de produção capitalista, não obstante seus prós e contras), e a segunda é a intensificação do período de labor do trabalhador, que passa a produzir dentro de uma mesma jornada uma quantidade maior de produtos/mercadorias.

Tal intensificação, pode ser analisada com base nas lições de Marx em um de seus escritos, de titulo "Salário, Preço e Lucro", partindo da premissa de que cada mercadoria tem seu valor (que não se confunde com o preço, pois este segundo Marx é mera expressão 
monetária do valor real da mercadoria, estando o preço sujeito a oscilações a miúde o faz divergir do valor da mercadoria) determinado pela quantidade de trabalho (trabalho médio socialmente necessário em determinado momento histórico) utilizado para sua produção.

A intensificação do trabalho num mesmo período de tempo, gerando uma produção maior com a mesma quantidade de horas de trabalho, acarreta uma diminuição do valor trabalho inserido em cada produto, e portanto, proporcionalmente ao valor dos produtos, o valor do trabalho sofre uma diminuição contínua.

\begin{abstract}
Se as respectivas quantidades de trabalho necessário para produzir as respectivas mercadorias permanecessem constantes, seriam também constantes seus valores relativos. Porém, assim não sucede. A quantidade de trabalho necessário para produzir uma mercadoria varia constantemente, ao variarem as forças produtivas do trabalho aplicado. Quanto maiores são as forças produtivas do trabalho, mais produtos se elaboram num tempo de trabalho dado; e quanto menores são, menos se produzem na mesma unidade de tempo. Se, por exemplo, ao crescer a população, se fizesse necessário cultivar terras menos férteis, teríamos que inverter uma quantidade maior de trabalho para obter a mesma produção, e isto faria subir, por conseguinte, o valor dos produtos agrícolas. Por outro lado, se um só fiandeiro, com os modernos meios de produção, ao fim do dia converte em fio mil vezes mais algodão que antes fiava no mesmo espaço de tempo com auxílio da roca, é evidente que, agora, cada libra de algodão absorverá mil vezes menos trabalho de fiação que dantes e, por conseqüência, o valor que o processo de fiação incorpora em cada libra de algodão será mil vezes menor. E na mesma proporção baixará o valor do fio. (MARX, 1988, p. 21)
\end{abstract}

Apesar dos impactos negativos do desenvolvimento tecnológico (que aqui frisamos para que se perceba a importância ou mesmo a imprescindibilidade de controlar efeitos negativos inevitáveis com instrumentos sociais e jurídicos adequados) não se pode olvidar a necessidade do desenvolvimento tecnológico e sua utilização com sabedoria para que ocorra de maneira salutar o progresso da humanidade, mas o leitor, ciente da inevitabilidade da evolução tecnológica e de seus benefícios não pode adotar uma posição imprevidente e fechar os olhos para as complexidades que se renovam e se combinam constantemente num movimento ascendente e criativo.

É observando as tendências do sistema capitalista, especialmente as de acumulação de capital e de desvalorização do trabalho, que têm surgido as mais diversas correntes politico-jurídicas de adaptação do direito do trabalho, apontando os direitos sociais como resistência ao progresso e às necessidades do capital.

No entanto, essas correntes observam o agora e de maneira imprevidente fecham os olhos para o passado, desejando um retorno ao modo de exploração de mão de obra estabelecido quando da revolução industrial, mediante a destruição de todos os mecanismos de proteção, apontados como entraves burocráticos dos quais se deve abrir mão por um ato 
de fé consubstanciado na crença de que a repetição dos mesmos passos de outrora produzirá desta feita não somente um resultado diferente, mas diametralmente oposto, de prosperidade digna e de uma utopia idílica.

Beber na fonte dos estudos das maiores autoridades no estudo multidisciplinar e transversal, porém especializado e esotérico, permite ao estudioso vislumbrar o que há por detrás do véu de sofismas defendido inclusive em alguns estudos de Direito do Trabalho, não obstante seja incoerente com a finalidade ou teleologia desse ramo autônomo do Direito bem como incondizente com sua evolução histórica e com sua busca pelo equilíbrio das relações jurídicas. Esse véu de sofismas é o que Marx chamaria de "aparência enganadora"

Não se deve perder de vista ao analisar a relação entre capital e trabalho, que o capitalista busca o lucro, e não poderia ser diferente, pois no sistema capitalista há uma característica (que Robert Kurz denomina de irracionalidade) que faz com que a saúde do capital seja mais importante do que a vontade ou a própria saúde do capitalista, pois não importa qual a formação moral do capitalista quando seu capital se insere no plano concorrencial interempresarial as necessidades do capital the retiram as possibilidades de escolha.

Diante da força hercúlea dos desígnios do capital hipostasiado, o preço do trabalho sofre a incidência de uma força centrípeta que inibe sua expansão, tendendo a mantê-lo no seu limite mínimo natural.

\footnotetext{
O valor da força de trabalho é formado por dois elementos, um dos quais puramente físico, o outro de caráter histórico e social. Seu limite mínimo é determinado pelo elemento físico, quer dizer, para poder manter-se e se reproduzir, para perpetuar a sua existência física, a classe operária precisa obter os artigos de primeira necessidade absolutamente indispensáveis à vida e à sua multiplicação. $\mathrm{O}$ valor destes meios de subsistência indispensáveis constitui, pois, o limite mínimo do valor do trabalho. Por outra parte, a extensão da jornada de trabalho também tem seus limites máximos, se bem que sejam muito elásticos. Seu limite máximo é dado pela força física do trabalhador. Se o esgotamento diário de suas energias vitais excede um certo grau, ele não poderá fornecê-las outra vez, todos os dias. Mas, como dizia, esse limite é muito elástico. Uma sucessão rápida de gerações raquíticas e de vida curta manterá abastecido o mercado de trabalho tão bem como uma série de gerações robustas e de vida longa. (MARX, 1988, p. 39)
}

Preferiu-se referir a esse limite como natural, pois o próprio Marx se refere a períodos em que, no passado, o trabalhador inglês se viu submetido ao pagamento de salários inferiores a esse limite mínimo, quando para sobreviver necessitava da assistência 
prestada pelas paróquias, permitindo relativamente sua sobrevivência e a reprodução da classe trabalhadora.

Elucidando as lições apontadas, nos referimos ao limite mínimo natural do salário como aquele valor que garanta a aquisição dos meios de subsistência do trabalhador, com ou sem certo nível de recomposição da força de trabalho a depender do momento histórico vivido por uma dada sociedade e das condições momentâneas do exército de reserva (ou superpopulação relativa) nesse mesmo dado momento.

A busca pela implementação desse limite mínimo é o que fundamenta grande parte dos diversos mecanismos de modificação do status quo (ou de um determinado status momentâneo) da relação entre capital e trabalho. A outra grande motivação é a adaptação dos procedimentos e da respectiva roupagem jurídica às novas tecnologias e técnicas de gestão para aumento da produtividade ou do lucro.

Seja com fundamento em um desses dois frequentes motivos, ou em algum motivo eventual, essas mudanças, para serem aceitas, são rotuladas por eufemismos, como atualização ou reforma. Sendo sua apresentação crucial para que o interprete a entenda como algo ruim com possíveis reflexos positivos ou algo bom com possíveis reflexos negativos. Que podemos comparar metaforicamente a um copo que pode estar meio vazio ou meio cheio a depender da expectativa do interprete, ou mesmo à utilização de um remédio que apresenta certo grau de toxidade como efeito colateral, que pode ser interpretado como um remédio que pode envenenar ou um veneno que pode curar a depender do conceito que se dê para os termos remédio e veneno.

\section{COMPREENSÃO E INTERPRETAÇÃO DA REFORMA TRABALHISTA A PARTIR DO ESCÓLIO DE MARX}

Uma dessas reformas, é a reforma trabalhista de 2017, implementada principalmente pela Lei 13.467/2017 e pela MP 808/2017, que é apresentada por seus defensores como sendo um fator motivador de investimentos estrangeiros no país, e para esse objetivo fim, os meios utilizados se apresentam como uma pletora de textos normativos em favor da parte mais forte na relação empregatícia, desequilibrando cada vez mais uma relação desigual por natureza, aproximando sua regulamentação de um padrão de regulamentação adotado para relações civis que se dão num plano de inequívoca igualdade entre os sujeitos. 
Mister enfatizar que as exceções que prevejam mais poderes para o empregador, a tentativa de aproximação do Direito do Trabalho ao Direito Civil ou a supressão de direitos trabalhistas antes consagrados em Lei ou na jurisprudência (ao arrepio do Princípio da vedação ao retrocesso) não podem ser encarados como uma mudança da ratio desse ramo autônomo do Direito.

Não há natureza principiológica nessas Exceções, especialmente tendo em vista a doutrina majoritária que vê os princípios como pilares do ramo cientifico que no plano jurídico funcionam como mandados de otimização, demandando sua aplicação na maior medida possível diante das possibilidades fáticas e jurídicas nos termos das lições do jurista alemão Robert Alexy.

Isso deve restar muito claro ao leitor diante da evolução histórica e da teleologia do Direito do Trabalho, como ramo do Direito que põe limites à autonomia privada para resguardar o equilibro da relação trabalhista mediante proteção da parte hipossuficiente, que é o trabalhador. Compreender de modo inverso se mostra no mínimo incoerente diante desse panorama, especialmente se tal compreensão vai de encontro aos comandos Constitucionais, como é o caso brasileiro.

No entanto, a reforma trabalhista de 2017 vem permitindo a renúncia de direitos de ordem pública (portanto, de relevância não apenas individual, mas coletiva, por sua observância refletir nos demais sujeitos da sociedade) antes tidos por indisponíveis e aumentando a intensidade do ritmo de trabalho, a instabilidade do trabalhador quanto ao montante de rendimentos que poderá auferir e atribuindo ao trabalhador uma parcela cada vez maior dos riscos dos empreendimentos empresariais, sem que estes possam se beneficiar na mesma proporção dos bônus decorrentes dessa álea.

Um instituto que é um retrato fiel de boa parte dessas mazelas supra relatadas é o contrato de trabalho intermitente. Convém observar que a contratação intermitente visa à utilização da força de trabalho de maneira descontinua de acordo com a demanda momentânea, de modo que os haveres do trabalhador passam a oscilar de acordo com a demanda oferecida por seu empregador.

Nessa circunstância adquire pertinência o já referido limite mínimo natural do salário e sua tendência de implementação em razão dos objetivos de lucro e acumulação do capital, pois quando a demanda estimada pelo empregador para gerar o pagamento nesse 
patamar não é alcançada ficam comprometidas a subsistência do trabalhador e a reprodução da força de trabalho.

Embora esteja em comento a reforma trabalhista de 2017, a contratação intermitente pode ser analisada por espécies de contratos firmados no passado a partir dos mesmos pressupostos de pagamento proporcional às horas de trabalho, descontinuidade $\mathrm{e}$ insegurança quanto à demanda de trabalho e ao montante total aferido pelo trabalhador ao final de um dado período de tempo. Vale ressaltar que no passado já foi feita análise desse tipo de contratação Marx, e convém verificar suas conclusões:

\begin{abstract}
Se o salário por hora é fixado de maneira que o capitalista não se vê obrigado a pagar um salário diário ou semanal, mas somente as horas de trabalho durante as quais ele decida ocupar o trabalhador, ele poderá ocupá-lo por um tempo inferior ao que serviu originalmente de base para o cálculo do salário por hora ou para a unidade de medida do preço do trabalho. Sendo essa unidade de medida determinada pela proporção valor diário da força de trabalho/jornada de trabalho de um dado número de horas, ela perde naturalmente todo sentido assim que a jornada de trabalho deixa de contar um número determinado de horas. A conexão entre o trabalho pago e o não pago é suprimida. $\mathrm{O}$ capitalista pode, agora, extrair do trabalhador uma determinada quantidade de mais-trabalho, sem conceder-lhe o tempo de trabalho necessário para sua autoconservação. Pode eliminar toda regularidade da ocupação e, de acordo com sua comodidade, arbítrio e interesse momentâneo, fazer com que o sobretrabalho mais monstruoso se alterne com a desocupação relativa ou total. Pode, sob o pretexto de pagar o "preço normal do trabalho", prolongar anormalmente a jornada de trabalho sem que haja qualquer compensação correspondente para o trabalhador. (MARX, 2013, p. 753-754)
\end{abstract}

Ressalvada a limitação constitucional da duração diária e semanal do trabalho, verifica-se que esse modo de contratação intermitente tem a consequência inexorável de aumento da intensidade da prestação do serviço, gerando a contratação do trabalhador exclusivamente para os horários sabidamente de pico de demanda, diminuindo o contingente de trabalhadores nos momentos de demanda inferior.

Desse modo toda a força de trabalho, seja ela intermitente ou não, empregado ou trabalhador lato sensu, permanente ou por tempo determinado, é mantida num ritmo de trabalho substancialmente mais acelerado do que aquele existente antes da consagração da possibilidade de pactuação dos contratos de trabalho intermitentes.

O aumento da intensidade da prestação dos serviços, além de aumentar a propensão do trabalhador ao acometimento por mazelas ocupacionais e ao envolvimento em incidentes e acidentes do trabalho; no plano do assalariamento o aumento da intensidade gera diminuição da vida laborativa do trabalhador e do valor do trabalho, o que ocorre mesmo quando eventualmente ocorra um aumento do valor nominal dos proventos obtidos pelo 
trabalhador ao final de determinado período (v.g. de um mês), proporcional ou inferior à proporção do aumento de intensidade.

Isso se dá porque a partir de determinado grau de extração da força de trabalho, os danos diferidos à saúde e a redução por exaustão da sobrevida laborativa do trabalhador progridem numa velocidade cada vez maior, podemos dizer, em progressão geométrica. Vejamos:

\begin{abstract}
Com a jornada de trabalho prolongada, o preço da força de trabalho pode cair abaixo de seu valor, embora nominalmente se mantenha igual, ou mesmo suba. Lembremos que o valor diário da força de trabalho é calculado com base em sua duração média, ou na duração normal da vida de um trabalhador e na correspondente transformação normal - ajustada à natureza humana - de substância vital em movimento. Até certo ponto, o desgaste maior da força de trabalho, inseparável do prolongamento da jornada de trabalho, pode ser compensado com uma remuneração maior. Além desse ponto, porém, o desgaste aumenta em progressão geométrica, ao mesmo tempo que se destroem todas as condições normais de reprodução e atuação da força de trabalho. O preço da força de trabalho e o grau de sua exploração deixam de ser grandezas reciprocamente comensuráveis. (MARX, 2013, p. 729)
\end{abstract}

A proporção dos danos causados à saúde do trabalhador e sua exposição a riscos decorrentes do trabalho, que variam de acordo com a natureza da atividade que é exercida e do ambiente de trabalho no qual ela é exercida se tornam vultosas e desproporcionais ao proveito econômico atribuído ao empregado, tornando essa relação excessivamente onerosa (usando o jargão civilista) com relação ao empregado.

Esse potencial danoso da superexploração do empregado não se revela uma grande surpresa, pois faz parte da relação empregatícia nos moldes em que concebida juridicamente na atualidade, que o proveito da atividade se destine ao tomador dos serviços (em regra, empregador).

Daí a importância de ressaltar o caráter protetivo do empregado inerente ao ramo justrabalhista, que regula uma relação pessoa física - empresa (observada a primazia da realidade sobre a forma), e não uma relação interempresarial, travada entre iguais com divisão de riscos e proveitos de maneira proporcional entre as partes. Em outras palavras, é o trabalhador que se arrisca e se desgasta em proveito de outrem, e o faz para sobreviver mediante a garantia da sua subsistência e de sua família com o suor do seu rosto e o labor de seus braços.

\title{
7 CONCLUSÕES
}

Rev. do Dir. do Trabalho e Meio Ambiente do Trabalho | e-ISSN: 2525-9857 | Salvador | v. 4 | n. 1 | p. 40 - 58 | Jan/Jun. 2018 
Verificou-se que a prestação laborativa se encontra inserida no sistema de produção capitalista, e que as características desse modo de produção, seja de obtenção de lucro, de tendência de acumulação de capital, ou ainda sua propensão a crises coloca o trabalhador e a relação jurídica de emprego em situação de constante pressão no contexto dessa tendência sistemática de acumulação.

As características do trabalho humano podem ser observadas em sua gênese, não sob o ponto de vista da caracterização da relação de emprego, mas num panorama geral de diferenciação de outras atividades passíveis de apropriação pelos meios de produção como as atividades dos animais, isso demanda uma análise histórico-sociológica que leva à necessidade de aferição do valor do trabalho e dos limites do preço que lhe é atribuído.

Os limites do preço do trabalho assumem especial relevância diante da questão social, na qual a exploração do trabalho ganha posição de destaque, sendo necessária a manutenção de um patamar de retribuição do trabalho capar de assegurar a subsistência/manutenção e a reprodução da classe trabalhadora.

A força do sistema capitalista tende à superexploração do trabalhador em razão da sua tendência à acumulação. Nessa toada, assume relevância impar para amenizar a questão social e para a promoção de um desenvolvimento social e econômico garantidor de um bem-estar social mínimo, a imposição de limites e a garantia de direitos aos trabalhadores.

É nesse contexto que se insere a reforma trabalhista de 2017, como uma decorrência da tendência de exploração crescente da mão de obra mediante aumento da duração e da intensidade do trabalho, bem como pela diminuição de seus custos em detrimento dos direitos dos trabalhadores.

Diante da evolução histórica e da teleologia do Direito do Trabalho, como ramo do Direito que põe limites à autonomia privada para resguardar o equilibro da relação trabalhista mediante proteção da parte hipossuficiente, que é o trabalhador, se mostra incoerente defender que as exceções que permitem renuncias a direitos trabalhistas, garantem poderes ao empregador ou retiram direitos antes consagrados pela Lei ou pela jurisprudência sejam princípios do Direito do Trabalho.

Não são essas excepcionalidades exigidas pelo direito de maneira expansiva mediante sua realização na maior medida possível. Elas não possuem as funções dos princípios e defender tal posição não encontra amparo na Constituição brasileira. Tal 
interpretação, data vênia, prega a transmutação do direito do trabalho em outro ramo do Direito sem qualquer amparo constitucional e em afronta ao valor social do trabalho.

Diante desse movimento (no que tange aos exageros interpretativos mais ideológicos do que jurídicos) de retrocesso nos direitos dos trabalhadores, resta clara a importância de reafirmação da imprescindibilidade do Direito do Trabalho para a construção de uma sociedade justa, livre e solidária. $\mathrm{O}$ desenvolvimento num contexto de bem-estar, exige as limitações e o equilíbrio das relações levado a efeito com o Direito do Trabalho. E o jurista e a sociedade não podem perder de vista sua relevância, sua teleologia e sua evolução histórica.

\section{REFERÊNCIAS}

BRAVERMAN, H. Trabalho e Capital Monopolista: a degradação do trabalho no século XX. Rio de Janeiro, Editora Guanabara, 1987. Páginas: 49-60.

GUIMARÃES, I. Reprodução e Trabalho, in IVO, Anete et all. Dicionário Temático desenvolvimento e questão social. Annablume, 2013, 422-428.

HARVEY, D. A superpopulação relativa in: Para entender o Capital, Livro 1, Boitempo, 2013, p. 267-275.

SINGER, Paul. Economia Política do Trabalho, SP, HUCITEC, 1977, p. 118-146.

SOMBRA, Thiago Luís Santos. A Eficácia dos Direitos Fundamentais nas Relações privadas. $2^{a}$ ed. São Paulo: Editora Atlas S.A., 2011.

IANNI, O. A questão social, São Paulo em Perspectiva, 5 (1), 1991. Disponível em: <http://produtos.seade.gov.br/produtos/spp/v05n01/v05n01_01.pdf> Acesso em: 02/09/2017.

MARX, Karl. O Capital: Crítica da economia política. Livro I: O processo de produção do capital. Trad. Rubens Enderle. São Paulo: Boitempo, 2013

MARX, Karl. Salário, Preço e Lucro. São Paulo: Nova Cultural, 1988. 